\title{
Bacterial programmed cell death of cerebral endothelial cells involves dual death pathways
}

\author{
Daniela Bermpohl, ${ }^{1}$ Annett Halle, ${ }^{1}$ Dorette Freyer, ${ }^{1}$ Emilie Dagand, ${ }^{1}$ Johann S. Braun, ${ }^{1}$ \\ Ingo Bechmann, ${ }^{2}$ Nicolas W.J. Schröder, ${ }^{3}$ and Joerg R. Weber ${ }^{1}$
}

${ }^{1}$ Department of Neurology, ${ }^{2}$ Department of Cell Biology and Neurobiology, Center of Anatomy, and 3Institut für Mikrobiologie und Hygiene, Charité — Universitätsmedizin Berlin, Berlin, Germany.

\begin{abstract}
Major barriers separating the blood from tissue compartments in the body are composed of endothelial cells. Interaction of bacteria with such barriers defines the course of invasive infections, and meningitis has served as a model system to study endothelial cell injury. Here we report the impressive ability of Streptococcus pneumoniae, clinically one of the most important pathogens, to induce 2 morphologically distinct forms of programmed cell death (PCD) in brain-derived endothelial cells. Pneumococci and the major cytotoxins $\mathrm{H}_{2} \mathrm{O}_{2}$ and pneumolysin induce apoptosis-like PCD independent of TLR2 and TLR4. On the other hand, pneumococcal cell wall, a major proinflammatory component, causes caspase-driven classical apoptosis that is mediated through TLR2. These findings broaden the scope of bacterial-induced PCD, link these effects to innate immune TLRs, and provide insight into the acute and persistent phases of damage during meningitis.
\end{abstract}

\section{Introduction}

Endothelial cells separate the blood from tissue compartments and form major barriers in the lung, kidney, liver, and brain. The blood-brain barrier (BBB) is of particular importance and is formed by a complex cellular network of endothelial cells, astroglia, pericytes, perivascular macrophages, and a basal lamina (1). Capillary endothelial cells are (a) a major cellular substrate of the BBB; (b) a potential site of entry for bacteria into the brain (2); (c) a source of inflammatory mediators (3); (d) participants in the inflammatory recruitment of leukocytes $(3,4)$; and (e) a critical part of the neural stem cell niche (5). The BBB is functionally (6) and structurally (7) injured in meningitis and in encephalopathy as a manifestation of sepsis in the brain (8).

There is increasing evidence that multiple types of programmed cell death (PCD) play a central role in the complex balance among invading bacteria, the immune system, and host cells leading to inflammation and tissue damage in infections (9-12). Apoptosis is characterized by the typical morphological changes of nuclear chromatin condensation and complete nuclear fragmentation (13). Usually caspases, in particular caspase-3, are activated. A second form of cell death, apoptosis-like PCD, is associated with condensation and incomplete fragmentation of chromatin, absence of caspase activation, and release of apoptosis-inducing factor (AIF) (14). While numerous reports describe the ability of bacteria to induce classical apoptosis, the participation of bacteria in more broadly defined PCD has not been well studied.

Evidence in animal models of meningitis suggests that significant neuronal injury arises from more than classical apoptosis alone (15). In experimental meningitis, inhibition of caspase activity only reduces the number of apoptotic neurons in the dentate

Nonstandard abbreviations used: AFC, 7-amino-4-trifluoromethyl coumarin; AIF, apoptosis-inducing factor; BBB, blood-brain barrier; BMEC, brain microvascular endothelial cell; $\mathrm{CbpA}$, choline-binding protein $\mathrm{Al}$; $\mathrm{PCD}$, programmed cell death; PCW, pneumococcal cell wall; siRNA, small interfering RNA; TMRE, tetramethylrhodamine ethyl ester.

Conflict of interest: The authors have declared that no conflict of interest exists.

Citation for this article: J. Clin. Invest. 115:1607-1615 (2005).

doi:10.1172/JCI23223. gyrus of the hippocampus by about 50\% (16). Pneumolysin and $\mathrm{H}_{2} \mathrm{O}_{2}$ have been identified as neurotoxins $(17,18)$ that drive cell death independent of caspase activation, most likely executed via AIF (18). Evidence in immature dendritic cells also indicates that intact pneumococci induce apoptosis in both a caspase-dependent and -independent fashion (10). We sought to map in detail a broader range of cell death relevant to bacterial injury of the BBB.

Streptococcus pneumoniae is the major pathogen causing community-acquired bacterial meningitis in children and adults (19). Surprisingly devastating, especially in the context of modern antibiotics, is the $34 \%$ mortality and the $52 \%$ morbidity of pneumococcal meningitis (20). One of the determining events in the course of the disease is damage of the BBB and the blood-CSF barrier (7). Meningitis is typically preceded by sustained bacteremia, and pneumococci localize to and cross the BBB into the subarachnoidal space (2). Thus, bacterial challenge of BBB cells in vitro is a clinically relevant, experimentally accessible model for the study of multiple PCD events during infection.

During meningitis, bacteria multiply in the subarachnoidal space but do not invade brain parenchyma until the end stage of disease. Thus, while bacteria do not directly contact neurons, they have intense contact with cells of the BBB and the blood-CSF barrier (21). Bacteria can damage endothelial cells during invasion (2) or kill at a distance by secreted toxins (17). In addition to cytotoxins, the pneumococcal cell wall (PCW), consisting of a multilayered network of peptidoglycan with attached teichoic acid, is also highly inflammatory (22-24). Phosphorylcholine on the PCW is recognized by C-reactive protein (25) and platelet-activating factor (PAF) receptor (26). PCW are constantly released by living bacteria and massively liberated after the use of cell wall-active antibiotics (27). Purified PCW induces meningeal inflammation in different animal models indistinguishable from meningitis caused by living bacteria in the early phase of the disease $(23,28)$. The clinical outcome of pneumococcal meningitis correlates with the concentration of PCW in the CSF (29). Thus, it is of clinical importance to understand not only the ability of intact bacteria to interact with PCD pathways, but also the activities of cell walls that persist at the site of infection long after bacteria are killed. We found that 

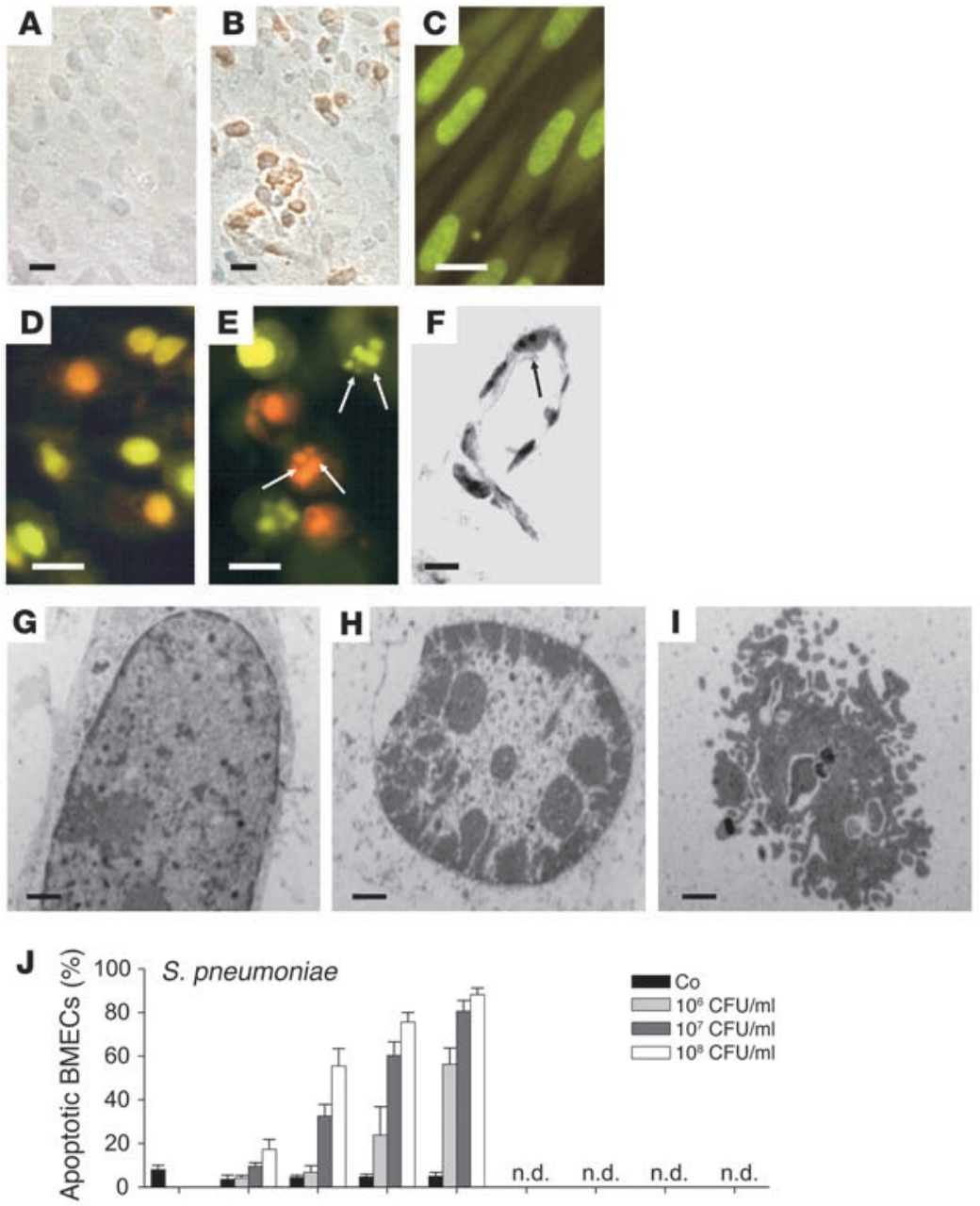

K

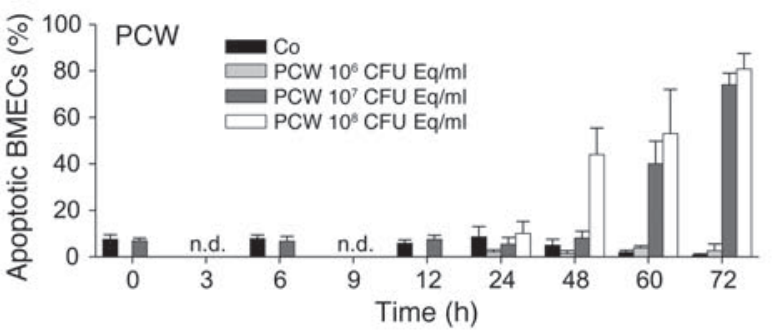

$\mathbf{L}$

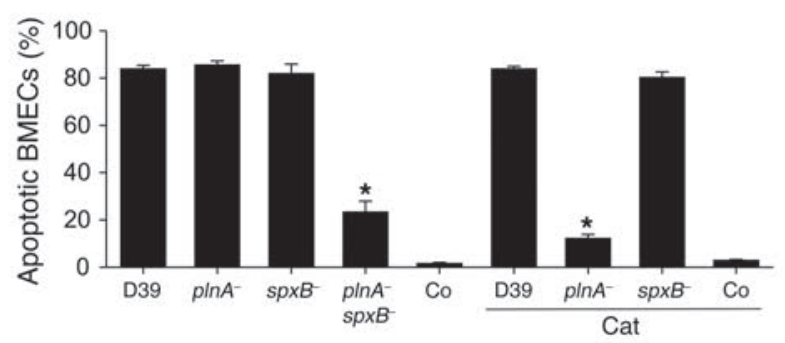

living pneumococci and PCW induces PCD in brain microvascular endothelial cells (BMECs) by 2 distinct mechanisms that occur over different time frames.

\section{Results}

Pneumococci and PCW induce apoptosis in BMECs. During disease, BBB cells are exposed to pneumococci and PCW, with PCW

\section{Figure 1}

Pneumococci and PCW trigger PCD in BMECs. (A and $\mathbf{C}$ ) Unchallenged BMECs. Living pneumococci (R6, $10^{7} \mathrm{CFU} / \mathrm{ml}, 12$ hours) induced the appearance of TUNEL-positive BMECs (B) and shrinkage and condensation of the nuclei by ethidium bromide/acridine orange staining (D). (E) BMECs incubated with PCW (107 CFU equivalents, 72 hours) underwent shrinkage, condensation, and fragmentation of the nuclei by ethidium bromide/acridine orange staining. Arrows indicate apoptotic bodies. (F) Pneumococci (D39) induced nuclear fragmentation (arrow) in endothelial cells of the vessel wall of capillaries in experimental mouse meningitis. (G) Electron microscopy showed a normal nucleus in the control culture. (H) Shrinkage and condensation of the nucleus occurred after challenge with living pneumococci (R6, $10^{7} \mathrm{CFU} / \mathrm{ml}, 4$ hours). (I) Nuclear fragmentation characterized PCD by PCW ( $10^{7} \mathrm{CFU}$ equivalents, 72 hours). Scale bars: $10 \mu \mathrm{m}(\mathbf{A}-\mathbf{F})$ and $1 \mu \mathrm{m}(\mathbf{G}-\mathbf{I})$. (J) Pneumococci (D39) caused dose- and time-dependent PCD in BMECs. No BMECs survived 18 hours after pneumococcal challenge. Co, control; n.d., not done. (K) PCW triggered a dose- and time-dependent protracted PCD. (L) The absence of 1 toxin, either pneumolysin $\left(p / n A^{-}\right)$or $\mathrm{H}_{2} \mathrm{O}_{2}$ $\left(s p \times B^{-}\right)$, did not prevent PCD compared with wild-type D39. Absence of both toxins significantly decreased PCD. Addition of catalase (Cat; $1,250 \mathrm{U} / \mathrm{ml}$ ) to $\mathrm{pln} A^{-}$ resulted in only a minor enhancement of protection of BMECs compared with $p / n A^{-} s p x B^{-}$after 12 hours. All data are presented as mean \pm SD. ${ }^{*} P<0.05$ (ANOVA and Student-Newman-Keuls test).

persisting at the site of infection well beyond the period of bacterial viability (29). To assess direct cytotoxic effects of pneumococci and PCW, we exposed primary BMECs to living bacteria (D39; $10^{6}, 10^{7}$ and $10^{8} \mathrm{CFU} / \mathrm{ml}$ ) or PCW (equivalent of $10^{6}, 10^{7}, 10^{8}$ and $10^{9} \mathrm{CFU} / \mathrm{ml}$ ) at concentrations relevant for human bacterial meningitis. Both living pneumococci and PCW induced morphologic and biochemical signs of apoptosis, such as cell shrinkage, condensation of nuclei, and the appearance of TUNEL in stained BMECs (Figure 1, A-E). In a mouse model of experimental meningitis, we found $0-2$ cells per screened section showing nuclear fragmentation in the vessel wall of capillaries of the neuropil (Figure 1F) and/or in the plexus choroideus in mice challenged intrathecally with pneumococci $\left(10^{4} \mathrm{CFU} \mathrm{D} 39,24\right.$ hours), whereas in sham-operated controls, we were not able to detect comparable endothelial cells $\left(P<0.05 ; \chi^{2}\right.$ test).

However, electron microscopy indicated differences between the 2 events (Figure 1, G-I). Living pneumococci caused an incomplete, lumpy chromatin condensation (Figure $1 \mathrm{H}$ ), whereas $\mathrm{PCW}$ induced a more advanced chromatin condensation, nuclear fragmentation, and formation of apoptotic bodies (Figure 1, E and I). Longer exposure (9 hours) to pneumococci caused the same morphological changes. Exposure to living bacteria (D39, $10^{7}$ and $10^{8} \mathrm{CFU} / \mathrm{ml}$ ) induced a rapid onset of apoptosis that reached a maximum of more than $80 \%$ of BMECs within 12 hours (Figure 1J), and no cells survived 
past 18 hours. In contrast, $\mathrm{PCW}$-induced cell death occurred much later, with a maximum at 72 hours (Figure $1 \mathrm{~K}$ ), and when the PCW concentration was increased to $10^{9} \mathrm{CFU} / \mathrm{ml}$, the effect was similar to that of $10^{8} \mathrm{CFU} / \mathrm{ml} \mathrm{PCW}$. Thus, while direct exposure of BMECs to living pneumococci or to PCW triggered apoptosis, the processes were strikingly different in morphology and time course.

Toxins secreted by living pneumococci cause apoptosis (17). Pneumococcal single mutants deficient in pneumolysin or $\mathrm{H}_{2} \mathrm{O}_{2}$ induced PCD of BMECs as efficiently as did the wild type. Only the absence of both toxins drastically decreased cell death of BMECs (Figure 1L). To eliminate a potential confounding effect of $\mathrm{H}_{2} \mathrm{O}_{2}$ produced by BMECs on pneumococcal-induced apoptosis, we added catalase to the culture. Apoptosis induced by the $\mathrm{H}_{2} \mathrm{O}_{2}$-producing pneumolysin-negative mutant strain $\left(p \ln A^{-}\right)$in the presence of catalase was only slightly lower than the double mutant (Figure 1L), which indicates that pneumococci are the major source of $\mathrm{H}_{2} \mathrm{O}_{2}$ and that there is only a minor contribution of oxidative products released by the BMECs themselves.

PCW but not living pneumococci activates caspases. To determine whether apoptosis caused by pneumococci or PCW was associated with caspase activation, we measured the activity of caspases 1-9. The exposure of BMECs to staurosporine, a strong inducer of apoptosis, activated all caspases tested (examples shown in Figure 2, A and C). Living pneumococci failed to activate all caspases measured in BMECs (examples shown in Figure 2, A and C). In contrast, PCW exposure led to the activation of caspase-3, with a maximum activity seen between 28 and 34 hours after stimulation (Figure 2B). The activation of the upstream caspase- 8 (Figure $2 \mathrm{D}$; staurosporine: $0.38 \pm 0.08 \mathrm{nmol} 7$-amino-4-trifluoromethyl coumarin $[\mathrm{AFC}] / \mathrm{mg}$ protein) and to a lesser extent caspase- 9 followed a similar time course (control vs. PCW: 6 hours, $0.02 \pm 0.02$ vs. $0.01 \pm 0.01 \mathrm{nmol} \mathrm{AFC} / \mathrm{mg}$ protein; 28 hours, $0.02 \pm 0.01$ vs. $0.22 \pm 0.15 \mathrm{nmol} \mathrm{AFC} / \mathrm{mg}$ protein, $P=0.001 ; 34$ hours, $0.01 \pm 0.01$ vs. $0.27 \pm 0.12 \mathrm{nmol} \mathrm{AFC} / \mathrm{mg}$ protein, $P=0.001)$. Caspase- $2,-6$, and -7 (data not shown), but, surprisingly, not caspase- 1 (control vs. PCW: 6 hours, $0.06 \pm 0.03$ vs. $0.04 \pm 0.03 \mathrm{nmol} \mathrm{AFC} / \mathrm{mg}$ protein; 28 hours, $0.04 \pm 0.01$ vs. $0.05 \pm 0.02 \mathrm{nmol} \mathrm{AFC} / \mathrm{mg}$ protein; 34 hours, $0.00 \pm 0.05$ vs. $0.04 \pm 0.01 \mathrm{nmol} \mathrm{AFC} / \mathrm{mg}$ protein), were also activated by PCW. PCW, but not pneumococci, led to the rapid cleavage of poly(ADP-ribose) polymerase (PARP), caspase- 3 (data not shown), and the calpain substrate fodrin between 28 and 38 hours after exposure (Figure 2, E and F).

To assess whether the caspase activation was of functional relevance, we incubated BMECs with living pneumococci $\left(10^{7} \mathrm{CFU} /\right.$ $\mathrm{ml}$ ) or PCW (equivalent of $10^{7} \mathrm{CFU} / \mathrm{ml}$ ) together with the broad-

\section{Figure 2}

Role of caspases in pneumococcal PCD. Living pneumococci failed to activate caspase-3 and caspase-9. Staurosporine (ST) activated both caspases (A and $\mathbf{C}$ ). PCW induced caspase- 3 and caspase- 8 activity ( $\mathbf{B}$ and $\mathbf{D}$; gray bars indicate PCW challenge; white bars indicate controls). AMC, 7-amino-4-methyl coumarin). Prot, protein. (E and F) According to Western blot analysis, in contrast to living pneumococci, staurosporine and PCW caused the cleavage of fodrin after exposure. (G) z-VAD-fmk (z-VAD), a broad-spectrum caspase inhibitor, and z-DEVD-cho (z-DEVD), a specific caspase-3 inhibitor, did not prevent PCD induced by living pneumococci (D39). Black bar: S. pneumoniae only. (H) Both inhibitors blocked PCD caused by PCW. Gray bar: PCW only. Data are presented as mean \pm SD. ${ }^{*} P<0.05$ (ANOVA and Student-Newman-Keuls test). spectrum caspase inhibitor $z-V A D-f m k$ or the specific caspase- 3 inhibitor z-DEVD-cho $(100 \mu \mathrm{M})$. Although $z$-VAD-fmk and z-DEVD-fmk prevented PCW-induced apoptosis, both inhibitors failed to suppress pneumococcal-induced (D39) apoptosis of BMECs (Figure 2, G and $\mathrm{H}$ ). These results suggest that pneumococci and PCW induce PCD by different mechanisms.

Pneumococci but not PCW trigger $\mathrm{Ca}^{2+}$ influx, mitochondrial damage, and release of AIF. Influx of $\mathrm{Ca}^{2+}$ or the release of $\mathrm{Ca}^{2+}$ from intracellular sources precedes morphologic changes of brain cell apoptosis induced by several agents (30), and overloading of mitochondria with $\mathrm{Ca}^{2+}$ induces permeability transition pores (31). We therefore evaluated whether living pneumococci or PCW trigger $\mathrm{Ca}^{2+}$ influx. As indicated by staining with Fluo-4, a dye that fluoresces upon binding to $\mathrm{Ca}^{2+}(32)$, living pneumococci (D39) induced a significant increase in intracellular $\mathrm{Ca}^{2+}$ after stimulation (Figure 3A). In contrast, intracellular $\mathrm{Ca}^{2+}$ did not increase after exposure to the mutant deficient in both pneumolysin and pyruvate oxidase $\left(p \ln A^{-} s p x B^{-}\right)$(Figure $3 \mathrm{~A}$ ) and $\mathrm{PCW}$ (Figure $3 \mathrm{~B}$ ).

We assessed mitochondrial damage triggered by pneumococci using a mitochondrion-selective fluorescent dye, uptake of which depends on an intact mitochondrial membrane. Mitochondrial uptake of this dye was markedly reduced within 4 hours of stimulation with pneumococci and dropped to $50 \%$ of control levels within 6 hours (Figure 3C), which indicates rapid mitochondrial dysfunction. Exposure to the double mutant $p \ln A^{-} s p x B^{-}$did not affect the mitochondrial function within 6 hours (Figure 3C).
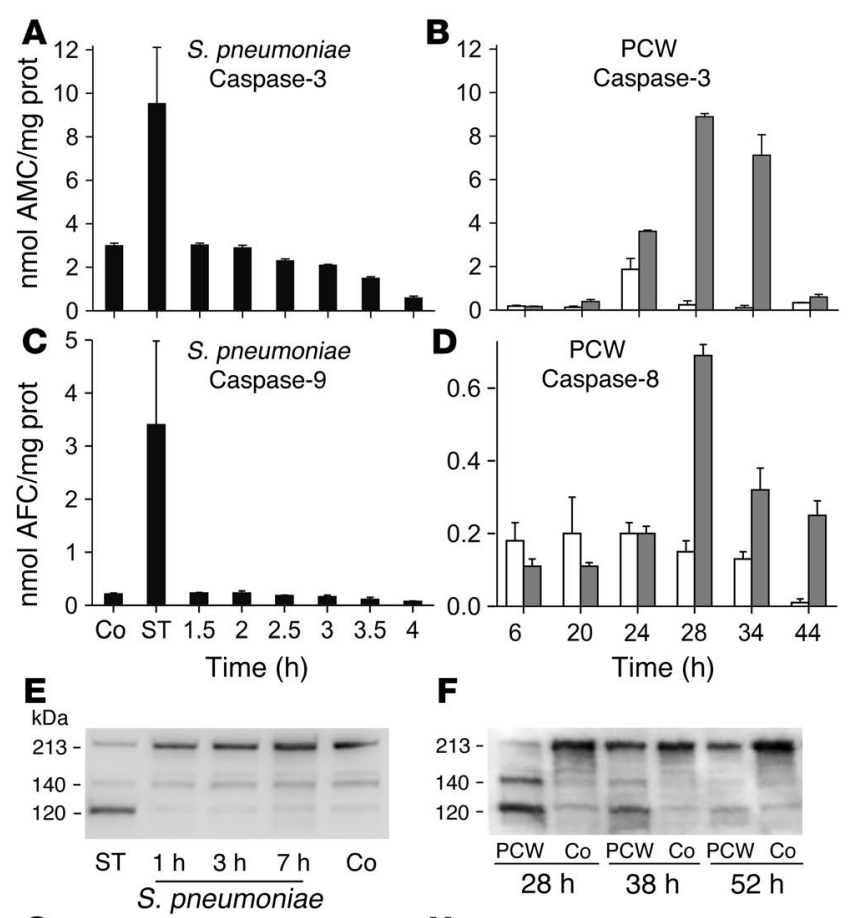

$\mathbf{F}$
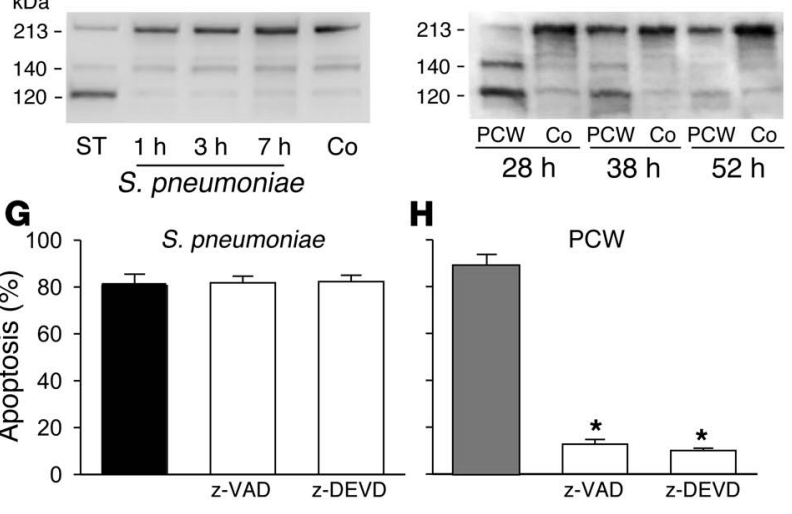

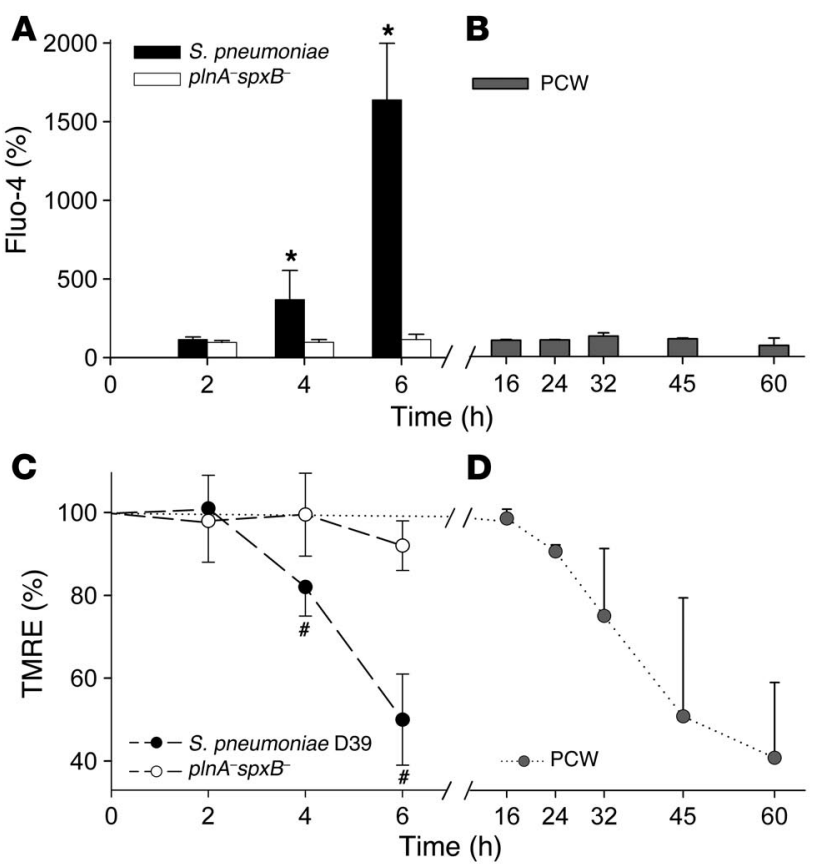

Exposure to PCW, in contrast to wild-type pneumococci (D39), resulted in a steady uptake of the dye that slowly declined beginning approximately 30 hours after exposure (Figure 3D).

Given the combination of early mitochondrial damage and lack of caspase activation by living pneumococci, we determined whether the loss of mitochondrial membrane potential was associated with the release of the proapoptotic factor AIF into the cytosol. Immunoblotting of mitochondrial and cytosolic fractions revealed the release of AIF from the mitochondrial into the cytosolic fraction (Figure 4C) 4 hours after incubation of cells with pneumococci.

Differences in DNA fragmentation. DNA fragmentation is a key feature of PCD. Within 4 hours after challenge, living pneumococci induced DNA fragmentation into large fragments of $50 \mathrm{kbp}$, as detected by pulsed-field gel electrophoresis (PFGE) (Figure 4A). Both the R6 and D39 strains induced an identical pattern. Exposure of BMECs to PCW induced delayed cell death and oligonucleosomal fragmentation of DNA into approximately 180-bp pieces, as detected by conventional gel electrophoresis (Figure 4B). The different patterns of DNA fragmentation provide additional evidence for 2 different death pathways induced by pneumococci and PCW.

$P C D$ is independent of adhesion. Pneumococcal choline-binding protein A ( CbpA), phosphorylcholine on the PCW, and the PAF receptor on the eurkaryotic cell participate in pneumococcal adhesion to host cells $(26,33)$. Challenge of BMECs with a pneumococcus deficient in CbpA and with wild-type D39 resulted in comparable numbers of apoptotic cells (Supplemental Figure 1; supplemental material available online with this article; doi:10.1172/JCI23223DS1).

\section{Figure 4}

DNA fragmentation and AIF translocation. (A) Pneumococci induced DNA fragmentation into large fragments of $50 \mathrm{kbp}$ starting 4 hours after challenge of BMECs. M, marker. (B) In contrast, PCW stimulation was followed by DNA fragmentation into approximately 180-bp pieces. (C) Exposure of BMECs to pneumococci $\left(10^{7} \mathrm{CFU} / \mathrm{ml}\right)$ resulted in a loss of mitochondrial (MIT) AIF over time and a shift into the cytosol (CYT) after 6 hours.

\section{Figure 3}

Influence of pneumococci and PCW on $\mathrm{Ca}^{2+}$ influx and the mitochondrial membrane potential. (A) Living pneumococci (D39, $10^{7} \mathrm{CFU} / \mathrm{ml}$ ) induced an increase of intracellular $\mathrm{Ca}^{2+}$ after exposure, which was not observed after exposure to $p \ln A^{-} s p x B^{-} .{ }^{*} P<0.01$ (Student's $t$ test), wild-type D39 versus $p \ln A^{-} s p x B^{-}$. (B) In contrast, PCW (107 CFU equivalents) had no effect on intracellular $\mathrm{Ca}^{2+}$ levels over time. (C) Living pneumococci caused a rapid loss of the selective mitochondrial fluorescent dye, which decreased $50 \%$ within 6 hours. $\# P<0.05$ (Student's $t$ test), wild-type D39 vs. spxB-plnA-. (D) PCW exposure resulted in a steady uptake of the dye that declined slowly over an extended time. All data are presented as mean \pm SD.

The same rates of apoptosis were induced by PCW lacking choline and therefore the ability to bind to the PAF receptor (Supplemental Figure 1). Additionally, purified pneumolysin as well as $\mathrm{H}_{2} \mathrm{O}_{2}$ were able to induce cell death in BMECs. Taken together, these data are consistent with the ability of pneumococci to induce PCD independent of adhesion-promoting factors.

Role of TLRs in pneumococcal- and PCW-induced PCD. TLRs are major sensors in the innate immune response (34). The inflammatory responses to heat-killed pneumococci, PCW, and pneumolysin involve TLRs $(35,36)$. To test the role of TLRs in PCD, we exposed HEK 293 cells stably transfected with human TLR2 (hTLR2) or hTLR4 to wild-type pneumococci. Pneumococci (D39) induced PCD independent of the presence of TLR4 and TLR2 in a time- (Figure 5, $A$ and D) and dose-dependent fashion (data not shown). To confirm that the rapid PCD induced by toxins from living bacteria was independent of TLRs, we designed an assay to isolate the effects of pneumolysin and its interaction with TLR4 by testing $s p x B^{-}$, a mutant producing pneumolysin but deficient in $\mathrm{H}_{2} \mathrm{O}_{2}$, against TLR4transfected cells (Figure 5B) and by testing $p \ln A^{-} s p x B^{-}$, a mutant deficient in both toxins, against TLR4-transfected cells (Figure 5B). Apoptosis induced by both strains was independent of the presence of TLR4. Additionally, the ability of purified pneumolysin to cause PCD was not modified by the presence of TLR4 (Figure 5C). Since PCW effects are of clinical importance, but occur in a much lon-
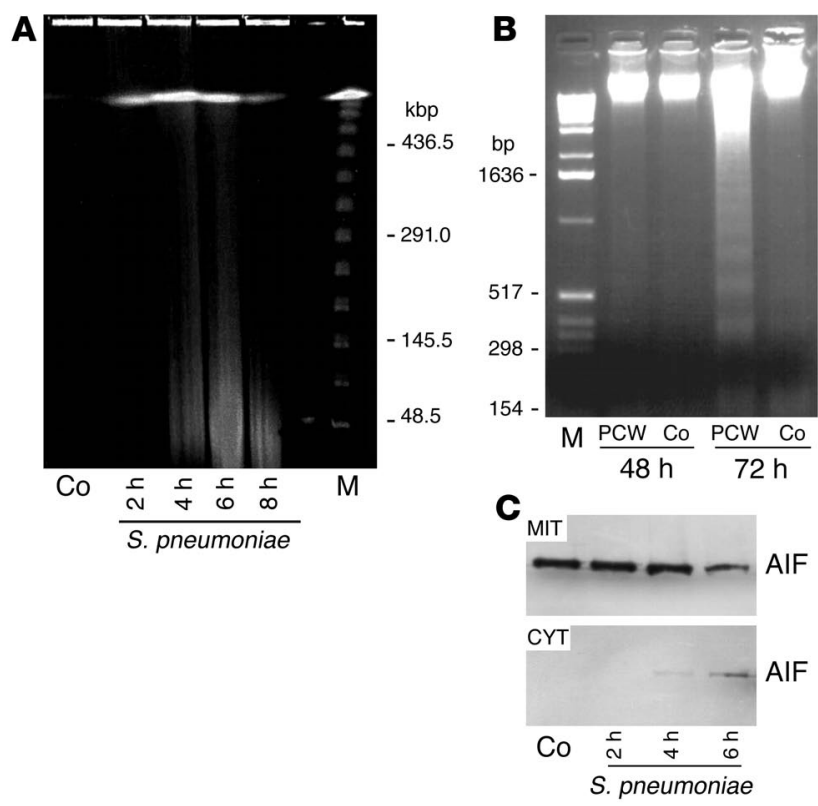
ger time frame than those of living bacteria, we examined the TLR dependence of non-toxin-induced PCD in TLR2-transfected cells. We observed an increase of apoptosis in HEK 293 cells transfected with hTLR2 after incubation with the toxin-defective pneumococcus (Figure 5D). Our data suggest that while pneumococcus and its toxins cause PCD in the absence of TLR4, components other than toxins most likely act through TLR2.

PCW is the major inflammatory component of the pneumococcal surface known to interact with TLR2 $(35,37)$. After incubation with PCW, only HEK 293 transfected with hTLR2 developed the morphological changes characteristic of classical apoptosis (Figure 5E). Cells transfected with hTLR4/MD2 or without TLRs did not die. The induction of apoptosis was more pronounced in HEK 293 cells cotransfected with hCD14 (data not shown). These results were confirmed with BMECs prepared from TLR2-knockout mice. After incubation with PCW, only wild-type BMECs showed the morphological changes of classical apoptosis, whereas BMECs deficient in TLR2 were protected (Figure 5F). Next we inhibited apoptosis induced by PCW with 2 different small interfering RNAs (siRNAs). A nonsilencing siRNA was not able to prevent the PCWinduced apoptosis in BMECs (Figure 5G). These experiments indicate that TLR2 is critical for PCW-associated apoptosis.

Role of TNF- $\alpha$ and FAS. Apoptosis can be initiated by the interaction of death receptors and their ligands (38). Since PCWinduced apoptosis was delayed and involved the activation of upstream caspase-8 (Figure 2D), we sought to rule out a receptor-mediated mechanism. Administration of a blocking anti-Fas receptor antibody $(5 \mu \mathrm{g} / \mathrm{ml})$ reduced $\mathrm{PCW}$-induced apoptosis about $10 \%$ but was not able to prevent it (Supplemental Figure 2 ). We have shown previously that BMECs release high amounts of TNF- $\alpha$ when challenged with PCW (3), but the administration of a blocking TNF- $\alpha$ antibody led to only a $10 \%$ decrease in apoptosis (Supplemental Figure 2).

\section{Discussion}

Despite the medical importance of endothelial cells in sepsis and other invasive bacterial diseases, our understanding of the molecular interactions of Gram-positive bacteria with such endothelial barriers as the BBB is incomplete. Clinically, structural damage

\section{Figure 5}

Role of receptors in pneumococcal-induced PCD. (A) Pneumococci (D39) induced cell death independent of the presence of TLR4. Pneumococci deficient in $\mathrm{H}_{2} \mathrm{O}_{2}$ (spxB-) induced cell death as effectively as did wild-type pneumococci (D39; A and B). (B) plnA-spxB- caused significantly less PCD that was not changed by the presence of TLR4. (C) Additionally, the ability of purified pneumolysin (pln) to cause PCD was not modified by the presence of TLR4. (D) HEK 293 cells were killed by wild-type pneumococci (D39) independent of the presence of TLR2. plnA-spxB-induced significantly more PCD in HEK 293 cells transfected with TLR2 after 6 and 9 hours. All data presented as mean \pm SD. ${ }^{*} P<0.05$, Student's $t$ test. (E) PCW (107 CFU equivalents) induced significantly more PCD in HEK 293 cells stably transfected with TLR2 at 24, 48 , and 72 hours. ${ }^{*} P<0.05$; Student's $t$ test. (F) PCW (107 CFU equivalents) caused PCD in wild-type BMECs, whereas PCW did not induce PCD in BMECs prepared from TLR2-deficient mice. ${ }^{* *} P<0.01$; Student's $t$ test. (G) Transfection with 2 different TLR2 siRNAs (1, TLR2-1; 2, TLR2-2) significantly reduced PCD compared with transfection with a nonsilencing RNA at 48 hours. Neg siRNA, nonsilencing control. $\# P<0.001$ (Student's $t$ test) in immortalized rat BMECs after incubation with PCW (107 CFU equivalents). of the BBB is a key event in meningitis and in sepsis-associated encephalopathy. Interaction of bacteria with endothelium of the $\mathrm{BBB}$ affects invasion of bacteria, recruitment of leukocytes, and local disruption of barrier functions. This report reveals the impressive ability of $S$. pneumoniae, clinically one of the most important pathogens, to induce 2 morphologically distinct forms of PCD in brain-derived endothelial cells. These events contribute to both acute and protracted damage during meningitis and are distinct from bacterial adhesion and the inflammatory process.

Living pneumococci induce PCD in BMECs beginning within hours and ending with total destruction of the monolayer within 12 hours. This overwhelming process is driven by the major bacterial toxins, $\mathrm{H}_{2} \mathrm{O}_{2}$ and pneumolysin, since elimination of both toxins prevented PCD. These findings agree with our previous data indicating that the interplay of both toxins induces apoptosis in neurons and microglia (17). Pneumococci caused apoptosis-like PCD, not classical apoptosis (13). This is supported by a number of features. Morphologically, cells experienced shrinkage and condensation but not complete fragmentation of the nucleus. In the context of these studies, the number of necrotic cells was low. Living pneumococci failed to activate caspases $1-10$, and caspase inhibitors did not prevent PCD - findings supported by previous observations in neurons and immune cells $(10,18)$. Rapid mitochondrial damage was followed by translocation of mitochondrial AIF into the cytoplasm. AIF has been suggested as a potential executor of pneumococcal-induced cell death in other cells (18). A role of AIF is compatible with the large-scale DNA fragmentation initiated by living pneumococci and is consistent with the morphological changes of apoptosis-like PCD (14). Initiation of apoptosis-like
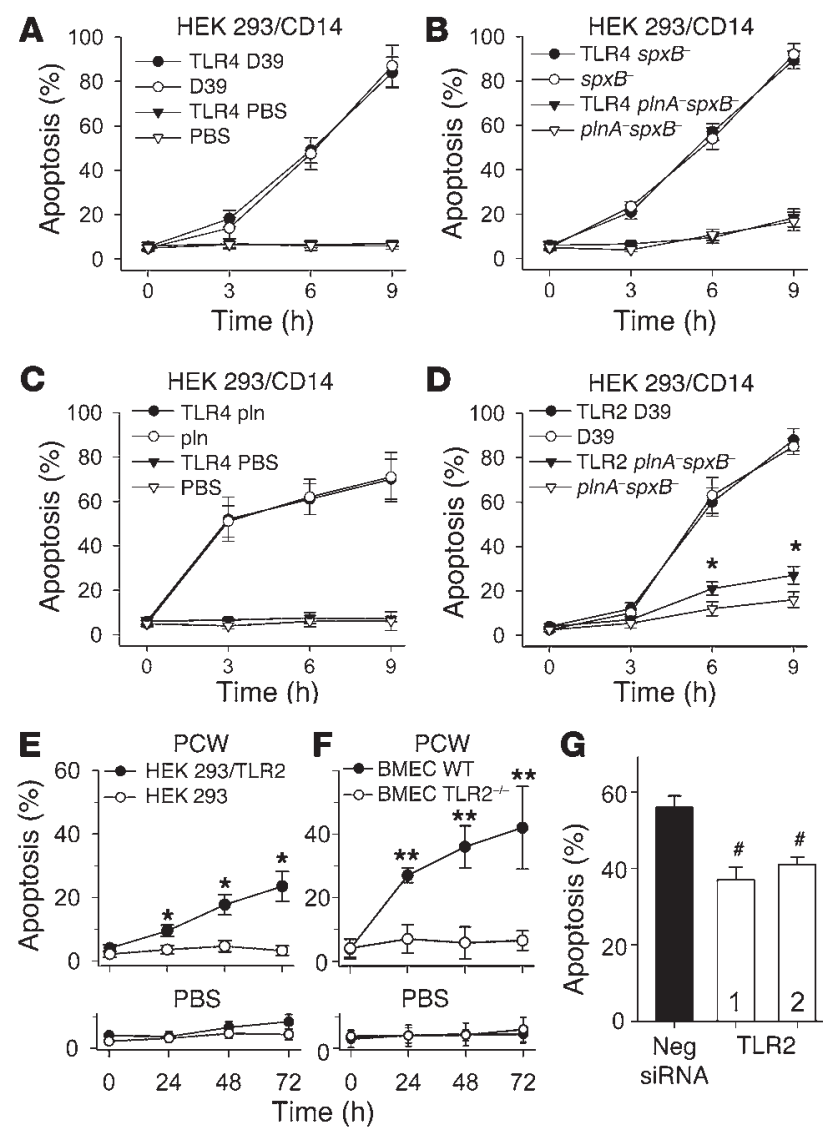


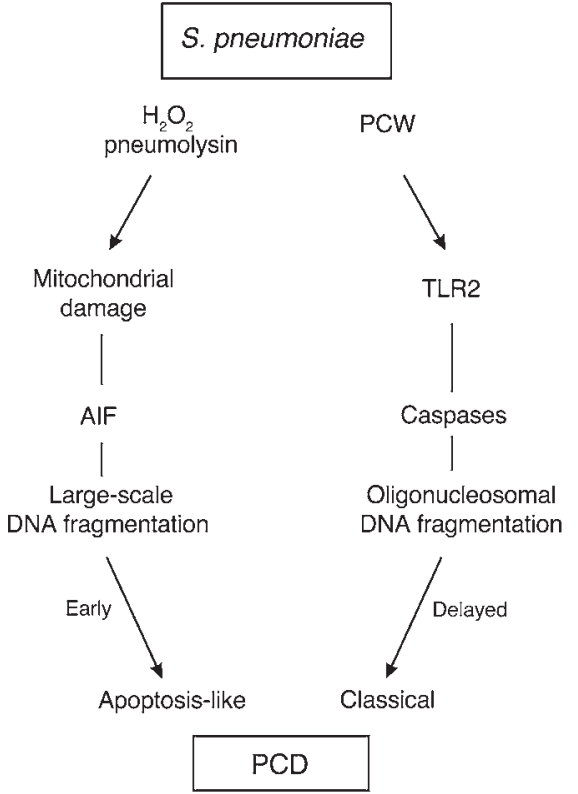

Figure 6

Dual pathways of pneumococcal-induced PCD. The major pneumococcal toxins $\mathrm{H}_{2} \mathrm{O}_{2}$ and pneumolysin result in mitochondrial damage followed by release of AIF, which executes early apoptosis-like PCD. In contrast, PCW induced PCD through TLR2 and activation of caspases resulting in DNA fragmentation and protracted classical apoptosis. Pneumococcus and released PCW have the ability to kill eukaryotic cells by 2 distinct mechanisms within different time frames and different morphological features.

PCD did not require adherence of bacteria to the target cell, consistent with the fact that this is achieved by secretion of toxins. Thus, adhesion- and invasion-promoting factors of the pneumococcus do not participate in PCD. The rapid onset of this process suggests a major role in $\mathrm{BBB}$ dysfunction during the acute phase of meningitis and would explain why caspase inhibitors show limited efficacy in experimental models of acute disease (16).

Upon initiation of antibiotic therapy, dying bacteria release a myriad of fragmented cell wall pieces (27). In both animal models and in human disease, this has been shown to invoke an intense inflammatory response $(23,24,28)$. Here we demonstrate for the first time to our knowledge that released PCW has the additional ability to initiate classical apoptosis. This ability of PCW is supported by morphology (complete condensation and advanced fragmentation of the nucleus) and documented cleavage of caspases. Confirming the functional relevance of caspase activation, $z-V A D-$ fmk and the more specific caspase- 3 inhibitor z-DEVD-cho prevented PCW-induced apoptosis. Induction of classical apoptosis by PCW appears to occur in a very protracted time frame. Such activity would not only perpetuate BBB injury but also significantly disrupt endothelial and neuronal repair during resolution of meningitis.

Living pneumococci and the major cytotoxins $\mathrm{H}_{2} \mathrm{O}_{2}$ and pneumolysin appear to kill BBB cells independent of the presence of TLRs. This is consistent with the ability of pneumococci to induce apoptosis in neurons, cells that do not express TLR2 and TLR4 $(39,40)$. Although the double mutant $p \ln A^{-} s p x B^{-}$caused only $30 \%$ of the apoptosis compared with the $\mathrm{H}_{2} \mathrm{O}_{2}$-deficient but pneumolysin-producing mutant $s p x B^{-}$, this difference was not affected by the presence of TLR4. TLR4 does not seem to be involved in either of the cell death pathways, despite its ability to signal inflammation in response to pneumolysin (36). This may indicate that the cytolytic activity of pneumolysin and the free permeability of cells to $\mathrm{H}_{2} \mathrm{O}_{2}$ induce PCD without a specific receptor. These data indicate that in the context of infection, bacterial adhesion, inflammation, and cell death in response to living pneumococci seem to be mediated by parallel but independent mechanisms.

In contrast to acute infection with living bacteria, TLR 2 comes into play initiating PCD in response to PCW, such as in the context of bacterial cell wall debris created after antibiotic treatment. This PCW activity is independent of choline recognition by the PAF receptor during bacterial invasion (26). The chemically highly purified and defined PCW (41) induced cell death only in the presence of TLR2. The ability of purified PCW to induce apoptosis late does not rule out the activity of other surface components such as lipoteichoic acid and lipoproteins in TLR2-mediated early events (42). Indications for such activity were seen in the TLR2-dependent increase of apoptosis in HEK 293 cells exposed to toxin-defective living bacteria. Although PCW activated caspase- 3 and caspase-8, interruption of TNF- $\alpha$ or Fas receptor death pathways did not decrease PCD. Thus, PCW induced apoptosis directly through TLR2 and not by released soluble mediators.

Pneumococcus is one of the most aggressive invasive pathogens, and our evidence indicates that it damages endothelial cells via 2 functionally and morphologically distinct pathways, apoptosislike PCD and classical apoptosis (Figure 6). Although damaged BMECs may be removed very quickly (43), we found apoptotic endothelial cells in capillaries and the plexus choroideus in mice with pneumococcal meningitis. Clinically, the substantial capability of pneumococcus to trigger PCD may explain the particularly extensive injury to barriers of the body during pneumococcal infection, e.g., brain edema in meningitis. Cell wall-active antibiotics are extremely efficient in killing bacteria but cause a release of cell walls and other bacterial components. These components keep inflammation going, fuel tissue destruction in later stages of disease, and impede repair. In particular, the concentration of PCW in the CSF is directly correlated to a poor outcome of meningitis (29). TLR2, a critical receptor in innate immune response, is directly involved in cell wall-associated endothelial cell death. The existence of 2 processes of PCD induced by pneumococci indicates broader capabilities of bacteria to kill human cells and indicates damage by events independent of bacterial invasion or inflammatory responses.

\section{Methods}

Cell culture systems. Primary cultures of BMECs were prepared from 3-week-old Wistar rats and TLR2-deficient and age matched wild-type mice, as previously described (3). The TLR2-deficient mice were bred and genotyped as described previously (44). Medium was substituted with Ham's F10 with $20 \% \mathrm{FCS}, 2 \mathrm{mM}$ L-glutamine, $100 \mathrm{U} / \mathrm{ml}$ penicillin, $100 \mu \mathrm{g} / \mathrm{ml}$ streptomycin, $2.5 \mu \mathrm{g} / \mathrm{ml}$ amphotericin B, $0.5 \mu \mathrm{g} / \mathrm{ml}$ vitamin C (Sigma-Aldrich), $8 \mu \mathrm{g} / \mathrm{ml}$ endothelial cell growth factor (Roche Diagnostics Corp.), and $80 \mu \mathrm{g} / \mathrm{ml}$ heparin. All cell culture media and supplements were purchased from Biochrom unless otherwise noted. The endothelial cells formed confluent monolayers after 6-8 days and were subsequently used for the experiments. Of the cells, $0.05 \%$ stained positive for glial fibrillary acidic protein and $1 \%$ for OX-42 and CD14. Approximately $99 \%$ of the cultivated cells stained positive for vWF VIII (DakoCytomation). For siRNA transfection experiments, we use immortalized BMECs (RBEC-6) as described previously (45).

Bacterial culture and PCW preparations. S. pneumoniae, (D39 capsular type 2 and R6, its nonencapsulated derivative [Rockefeller University]), the CbpA- 
deficient mutant $c b p A^{-}$(33), the pneumolysin-negative mutant $p \ln A^{-}$(46), the pyruvate oxidase mutant $s p x B^{-}(47)$, and a $p \ln A^{-} s p x B^{-}$double mutant (17) were grown in medium containing casein and yeast. Mutant strains were grown in the presence of erythromycin $(1 \mu \mathrm{g} / \mathrm{ml})$ and the double mutant additionally with chloramphenicol $(2 \mu \mathrm{g} / \mathrm{ml})$. Bacteria were cultured overnight in chemically defined media to approximately $5 \times 10^{8}$ $\mathrm{CFU} / \mathrm{ml}$. Bacteria were pelleted, resuspended in cell culture medium, and incubated with BMECs for 1-12 hours. Bacterial multiplication continued slowly under these conditions (1 log every 6 hour).

PCW was purified as previously described (23), with minor modifications. Unencapsulated S. pneumoniae R6 was cultured in chemically defined medium, heat-killed, and disintegrated 2 times for 3 minutes with a Bead Beater apparatus (Roth) using 0.1-mm beads. The suspension was digested with $10 \mu \mathrm{g} / \mathrm{ml}$ DNAse (Promega) and $50 \mu \mathrm{g} / \mathrm{ml}$ RNAse (USB Corp.) for 1 hour at $37^{\circ} \mathrm{C}$ followed by treatment with $100 \mu \mathrm{g} / \mathrm{ml}$ trypsin (plus $10 \mathrm{mM}$ $\mathrm{CaCl}_{2}$; Sigma-Aldrich) for 2 hours at $37^{\circ} \mathrm{C}$. The digest was sedimented by centrifugation $(23,000 \mathrm{~g}, 20$ minutes) and resuspended in $2 \%$ SDS (Serva Electrophoresis $\mathrm{GmbH}$ ) at $90^{\circ} \mathrm{C}$ for 20 minutes followed by 8 cycles of washing. The purified cell walls were resuspended in $\mathrm{PBS}$ at $\mathrm{OD}_{620 \mathrm{~nm}}=1$ (equivalent of $10^{8} \mathrm{CFU}$ ) and were stored at $-20^{\circ} \mathrm{C}$. The composition of the cell wall has been described previously (48).

The ethanolamine-containing cell wall (R6EA) was prepared by an identical procedure, except that choline was replaced by $20 \mu \mathrm{g} / \mathrm{ml}$ ethanolamine (Sigma-Aldrich) in the growth medium (49).

Mouse model of pneumococcal meningitis. We used a previously published mouse model of pneumococcal meningitis (50). C57BL/6 mice, 15-20 grams in body weight, were anesthetized with isoflurane, and infection was induced by injecting $10^{4} \mathrm{CFU}$ S. pneumoniae D39 in $20 \mu \mathrm{l} \mathrm{PBS}$ (or $20 \mu \mathrm{l}$ PBS for controls; $n=3$ per group) by lumbar puncture. Mice were anesthetized again at 24 hours after infection, and CSF was analyzed to confirm bacterial growth. The mice were perfused transcardially with $3 \%$ paraformaldehyde. The brains were removed, postfixed and embedded in paraffin, cut into sections $5 \mu \mathrm{m}$ in thickness, and Nissl stained. Twentyfour comparable sections were screened for endothelial cells in the vessel wall, revealing nuclear fragmentation as morphological hallmark of PCD. Animal experiments were approved by the Landesamt für Arbeitsschutz, Gesundheitschutz und technische Sicherheit, Berlin, Germany.

Differentiation of living, apoptotic, and necrotic cell death. Ethidium bromide and acridine orange (Sigma-Aldrich) are fluorescent intercalating DNA dyes that allow for differentiation of living, apoptotic, and necrotic cells (51). Additionally, an in situ cell death TUNEL detection kit was used as described by the manufacturer (Roche Diagnostics Corp.). To confirm the morphological changes of apoptosis, we performed electron microscopy of BMECs after pneumococcal challenge. BMECs were fixed in $2.5 \%$ glutaraldehyde in $100 \mathrm{mM}$ cacodylate buffer overnight at $4^{\circ} \mathrm{C}$, postfixed, dehydrated, and embedded as described previously (17).

Fluorometric analysis of caspase activities. Cells were lysed in $10 \mathrm{mM}$ Tris- $\mathrm{HCl}$ (pH 7.5), $10 \mathrm{mM} \mathrm{NaH} \mathrm{PO}_{4} / \mathrm{NaHPO}_{4}$ (pH 7.5), $130 \mathrm{mM} \mathrm{NaCl}, 1 \%$ Triton $\mathrm{X}-100$, and $10 \mathrm{mM}$ sodium pyrophosphate for 5 minutes. Twenty microliters lysate was added to $80 \mu \mathrm{l}$ of reaction buffer (100 mM HEPES, $10 \%$ sucrose, $10 \mathrm{mM}$ dithiothreitol, and $0.5 \mathrm{mM}$ EDTA; pH 7.5) containing a specific fluorogenic caspase substrate $(75 \mu \mathrm{M}$; Calbiochem). After cells were incubated at $37^{\circ} \mathrm{C}$ for 60 minutes, a microplate reader (CytoFluor; Applied Biosystems) was used to measure fluorescence. Standard 7-amino-4-methyl coumarin and AFC solutions were used to calculate caspase activity.

Western blotting. BMECs were incubated 2-6 hours with pneumococci or for 24-60 hours with PCW. Cells were pelleted by centrifugation (153 g, 5 minutes, at $\left.4^{\circ} \mathrm{C}\right)$, and pellets were lysed on ice in RIPA buffer $(50 \mathrm{mM}$ Tris, $150 \mathrm{mM} \mathrm{NaCl}, 1 \%$ Triton X-100, $0.1 \%$ SDS, and $1 \%$ sodium deoxycholate) with $10 \mathrm{mg} / \mathrm{ml}$ protease inhibitor mixture (Sigma-Aldrich). The protein extracts were boiled for 5 minutes, separated by SDS-PAGE, and transferred to a polyvinylidene fluoride membrane. After the blots were blocked in Tris-buffered saline with $0.1 \%$ Tween and $5 \%$ nonfat milk, they were incubated with primary antibodies overnight at $4{ }^{\circ} \mathrm{C}$. We used the following antibodies: anti-fodrin (1:500) and anti-AIF (1:500; Santa Cruz Biotechnology Inc.). After being rinsed, the blots were incubated with a HRP-conjugated secondary antibody $(1: 5,000)$ and were developed by use of the ECL kit (Amersham Biosciences). For AIF localization studies, mitochondrial and cytosolic fractions were prepared as previously described (52).

Measurement of intracellular calcium. Increases in intracellular $\mathrm{Ca}^{2+}$ levels were monitored by Fluo-4. After incubation with pneumococci or PCW, BMECs were incubated with Fluo-4 (Invitrogen Corp.; $10 \mu \mathrm{M}$, for 45 minutes) and intracellular $\mathrm{Ca}^{2+}$ levels were determined by fluorescence. Fluo- 4 was measured with a multiwell fluorescence plate reader (excitation 485 $\mathrm{nm}$, emission $520 \mathrm{~nm})$.

Estimation of mitochondrial membrane potential. Tetramethylrhodamine ethyl ester (TMRE) is a cationic, lipophilic dye that accumulates in the negatively charged mitochondrial matrix according to the Nernst equation potential. A TMRE (Invitrogen Corp.) stock was prepared at a concentration of $10 \mathrm{mg} / \mathrm{ml}$ in DMSO and stored at $-20^{\circ} \mathrm{C}$. Working stocks of 1 $\mathrm{mg} / \mathrm{ml}$ were made up fresh in distilled water. For estimation of membrane potential $\left(\Delta \Psi_{\mathrm{m}}\right)$, cells were incubated with $100 \mathrm{nM}$ TMRE for 30 minutes at room temperature in cell culture medium at the end of the experiment. Cells were then washed 3 times with PBS, and a microplate reader was used to measure TMRE fluorescence (excitation $549 \mathrm{~nm}$, emission $574 \mathrm{~nm}$ ).

Pulsed field gel electrophoresis and internucleosomal DNA fragmentation. PFGE was performed as described previously (53). In brief, DNA was prepared from agarose plugs $\left(1 \times 10^{6}\right.$ cells $)$, digested twice with proteinase $\mathrm{K}(1 \mathrm{mg} /$ $\mathrm{ml} ; 50^{\circ} \mathrm{C}$; 36 hours) in NDS buffer $(0.5 \mathrm{M}$ EDTA, $10 \mathrm{mg} / \mathrm{ml}$ lauroyl sarcosine), and washed in $0.5 \times$ tris-boric acid-EDTA buffer, and this was followed by electrophoresis in a Bio-Rad CHEF-DR II (Bio-Rad Laboratories; $1 \%$ agarose; $0.5 \times \mathrm{TBE} ; 190 \mathrm{~V} ; 24$ hours; pulse wave 60 seconds; $120^{\circ}$ angle). Molecular weight standards ( $\lambda$ Ladder PFG Marker and Low Range PFG Marker) were from New England Biolabs.

Agarose gel electrophoresis of internucleosomal DNA fragmentation, following exposure of BMECs to pneumococci or PCW, was performed as described previously (54). We isolated DNA from BMECs $\left(10^{6}\right)$ using a genomic DNA isolation kit (Invitrogen Corp.) according to the manufacturer's instructions.

Transfection and stimulation of HEK293 cells. HEK 293 cells stably transfected with hTLR2 and hTLR4 together with hMD2 or an empty control vector (pcDNA3.1; kindly provided by E. Latz, University of Massachusetts Medical Center, Worcester, Massachusetts, USA) (55) were maintained in DMEM with $10 \%$ FCS and $0.5 \mathrm{mg} / \mathrm{ml} \mathrm{G} 418$ (Sigma-Aldrich). Depending on the experiment, we additionally transfected these cells with hCD14 $(50 \mathrm{ng})$ and/or $\beta$-galactosidase $(0.1 \mu \mathrm{g})$ and the ELAM NF-кB luciferase reporter plasmid $(0.25 \mu \mathrm{g}$; all plasmids were a kind gift of C.J. Kirschning, Munich, Germany) employing $2 \mu \mathrm{l}$ /well Lipofectamine transfection reagent (Invitrogen Corp.). As a control, the latter were challenged with ultrapure E. coli LPS (strain O111:B4; $100 \mathrm{ng} / \mathrm{ml}$; InvivoGen, Cayla SAS Belgium) Pam ${ }_{3}$ Cys lipopeptide (100 ng/ml; EMC Microcollections GmbH) or PCW (107 CFU equivalents) in DMEM without FCS.

siRNAtransfection of BMECs. RNA interference of TLR2 was performed using 21-bp (including a 2-deoxynucleotide overhang) siRNA duplexes (QIAGEN). The coding strands for TLR2 siRNA were CGAAGUCUACAGUCAAUUAdTdT (TLR2-1) and GCAAGAUAAUGAACACUAA-dTdT (TLR2-2). A nonsilencing siRNA, 3' fluorescein-labeled (QIAGEN), was used as a negative control. For transfection, immortalized BMECs (RBEC-6) (45) were seeded in 96-well plates and transfected at $80 \%$ confluency with siRNA duplexes (15 pmol/well) using Lipofectamine 2000 (Invitrogen Corp.) according to the manufacturer's recommendations. Assays were 
performed 24 and 48 hours after transfection. Downregulation of TLR2 mRNA was confirmed by RT-PCR followed by real-time PCR.

Cell stimulation protocol and statistical analysis. On the day of the experiment, BMEC media were replaced by $400 \mu \mathrm{l} /$ well of serum-free media (Invitrogen Corp.). For stimulation, $20 \mu \mathrm{l}$ (correlating to $10^{7} \mathrm{CFU}$ equivalents) of PCW suspension or encapsulated S. pneumoniae (D39) were added unless otherwise noted. Pneumolysin $(1 \mu \mathrm{g} / \mathrm{ml})$, purified as previously described (17), and $\mathrm{H}_{2} \mathrm{O}_{2}(2 \mathrm{mM}$; Merck KG) were used in previously described concentrations (18). For caspase inhibition experiments, $100 \mu \mathrm{M}$ z-VAD-fmk or 100 $\mu \mathrm{M} z$-DEVD-cho (Calbiochem) were added 1 hour prior to PCW or living pneumococci. For inhibition experiments, $2 \mu \mathrm{l}$ of a neutralizing polyclonal anti-TNF- $\alpha$ antibody (3), anti-Fas antibody ( $5 \mu \mathrm{g} / \mathrm{ml}$; Kamiya Biomedical Co.), or anti-PAF receptor antibody ( $5 \mu \mathrm{M}$; Biomol International LP) were administered 1 hour prior to stimulation with PCW.

The figures show representative experiments from 3 to 4 independent experiments, each using triplicate or quadruplicate wells. For descriptive statistics, data are expressed as mean \pm SD. Statistical analysis was performed with SigmaStat version 2.03 (SPSS Inc.). The tests used are stated in the figure legends.

\section{Acknowledgments}

We thank Renate Gusinda, Claudia Muselmann, and Cordula Mahrhofer for excellent technical assistance; Ralf Schumann (Berlin) for continuing help with the transfection systems; and Shizuo Akira (Osaka) for providing TLR2-deficient mice. This work was supported by grants from the Deutsche Forschungsgemeinschaft (SFB 507) and the Meningitis Research Foundation as well as the Hermann and Lilly Schilling Foundation.

Received for publication August 31, 2004, and accepted in revised form March 23, 2005.

Address correspondence to: Joerg R. Weber, Department of Neurology, Charité - Universitätsmedizin Berlin, Schumannstr. 20/21, 10117 Berlin, Germany. Phone: 49-30-450-560104; Fax: 49-30-450560942; E-mail: joerg.weber@charite.de.

Daniela Bermpohl and Annett Halle contributed equally to this work.
1. Bradbury, M.W. 1985. The blood-brain barrier Transport across the cerebral endothelium. Circ. Res. 57:213-222.

2. Ring, A., Weiser, J.N., and Tuomanen, E.I. 1998 Pneumococcal trafficking across the blood-brain barrier. Molecular analysis of a novel bidirectional pathway. J. Clin. Invest. 102:347-360.

3. Freyer, D., et al. 1999. Cerebral endothelial cells release TNF-alpha after stimulation with cell walls of Streptococcus pneumoniae and regulate inducible nitric oxide synthase and ICAM-1 expression via autocrine loops. J. Immunol. 163:4308-4314.

4. Springer, T.A. 1990. Adhesion receptors of the immune system. Nature. 346:425-434.

5. Shen, Q., et al. 2004. Endothelial cells stimulate self-renewal and expand neurogenesis of neural stem cells. Science. 304:1338-1340.

6. Quagliarello, V.J., Ma, A., Stukenbrok, H., and Palade, G.E. 1991. Ultrastructural localization of albumin transport across the cerebral microvasculature during experimental meningitis in the rat. J. Exp. Med. 174:657-672.

7. Quagliarello, V.J., Long, W.J., and Scheld, W.M. 1986. Morphologic alterations of the blood-brain barrier with experimental meningitis in the rat. Temporal sequence and role of encapsulation. J. Clin. Invest. 77:1084-1095.

8. Davies, D.C. 2002. Blood-brain barrier breakdown in septic encephalopathy and brain tumours. J. Anat. 200:639-646.

9. Zychlinsky, A., and Sansonetti, P. 1997. Perspectives series: host/pathogen interactions. Apoptosis in bacterial pathogenesis. J. Clin. Invest. 100:493-495.

10. Colino, J., and Snapper, C.M. 2003. Two distinct mechanisms for induction of dendritic cell apoptosis in response to intact Streptococcus pneumoniae. J. Immunol. 171:2354-2365.

11. Hotchkiss, R.S., Tinsley, K.W., Swanson, P.E., and Karl, I.E. 2002. Endothelial cell apoptosis in sepsis [review]. Crit. Care Med. 30:S225-S228.

12. Hotchkiss, R.S., et al. 2000. Caspase inhibitors improve survival in sepsis: a critical role of the lymphocyte. Nat. Immunol. 1:496-501.

13. Leist, M., and Jaattela, M. 2001. Four deaths and a funeral: from caspases to alternative mechanisms. Nat. Rev. Mol. Cell Biol. 2:589-598.

14. Susin, S.A., et al. 1999. Molecular characterization of mitochondrial apoptosis-inducing factor. Nature. 397:441-446.

15. Mitchell, L., et al. 2004. Dual phases of apoptosis in pneumococcal meningitis. J. Infect. Dis. 190:2039-2046.
16. Braun, J.S., et al. 1999. Neuroprotection by a caspase inhibitor in acute bacterial meningitis. Nat. Med. 5:298-302.

17. Braun, J.S., et al. 2002. Pneumococcal pneumolysin and $\mathrm{H}(2) \mathrm{O}(2)$ mediate brain cell apoptosis during meningitis. J. Clin. Invest. 109:19-27. doi:10.1172/ JCI200212035

18. Braun, J.S., et al. 2001. Apoptosis-inducing factor mediates microglial and neuronal apoptosis caused by pneumococcus. J. Infect. Dis. 184:1300-1309.

19. Schuchat, A., et al. 1997. Bacterial meningitis in the United States in 1995. Active Surveillance Team. N. Engl. J. Med. 337:970-976.

20. de Gans, J., and van de Beek, D. 2002. Dexamethasone in adults with bacterial meningitis. N. Engl. J. Med. 347:1549-1556.

21. Leib, S.L., and Tauber, M.G. 1999. Pathogenesis of bacterial meningitis [review]. Infect. Dis. Clin. North Am. 13:527-548.

22. Tomasz, A. 1981. Surface components of Streptococcus pneumoniae. Rev. Infect. Dis. 3:190-211.

23. Tuomanen, E., Liu, H., Hengstler, B., Zak, O., and Tomasz, A. 1985. The induction of meningeal inflammation by components of the pneumococcal cell wall. J. Infect. Dis. 151:859-868.

24. Weber, J.R., Moreillon, P., and Tuomanen, E.I. 2003. Innate sensors for Gram-positive bacteria. Curr. Opin. Immunol. 15:408-415.

25. Winkelstein, J.A., and Tomasz, A. 1978. Activation of the alternative complement pathway by pneumococcal cell wall teichoic acid. J. Immunol. 120:174-178.

26. Cundell, D.R., Gerard, N.P., Gerard, C., IdanpaanHeikkila, I., and Tuomanen, E.I. 1995. Streptococcus pneumoniae anchor to activated human cells by the receptor for platelet-activating factor. Nature. 377:435-438

27. Fischer, H., and Tomasz, A. 1984. Production and release of peptidoglycan and wall teichoic acid polymers in pneumococci treated with beta-lactam antibiotics. J. Bacteriol. 157:507-513.

28. Weber, J.R., Angstwurm, K., Bürger, W., Einhäupl, K.M., and Dirnagl, U. 1995. Anti ICAM-1 (CD54) monoclonal antibody reduces inflammatory changes in experimental bacterial meningitis. J. Neuroimmunol. 63:63-68.

29. Schneider, O., Michel, U., Zysk, G., Dubuis, O., and Nau, R. 1999. Clinical outcome in pneumococcal meningitis correlates with CSF lipoteichoic acid concentrations. Neurology. 53:1584-1587.

30. Lipton, S.A., and Nicotera, P. 1998. Calcium, free radicals and excitotoxins in neuronal apoptosis.
Cell Calcium. 23:165-171.

31. Crompton, M. 1999. The mitochondrial permeability transition pore and its role in cell death. Biochem. J. 341:233-249.

32. Chambers, J., et al. 1999. Melanin-concentrating hormone is the cognate ligand for the orphan G-proteincoupled receptor SLC-1. Nature. 400:261-265.

33. Rosenow, C., et al. 1997. Contribution of novel choline-binding proteins to adherence, colonization and immunogenicity of Streptococcus pneumoniae. Mol. Microbiol. 25:819-829.

34. Kopp, E., and Medzhitov, R. 2003. Recognition of microbial infection by Toll-like receptors. Curr. Opin. Immunol. 15:396-401.

35. Weber, J.R., et al. 2003. Recognition of pneumococcal peptidoglycan: an expanded, pivotal role for LPS binding protein. Immunity. 19:269-279.

36. Malley, R., et al. 2003. Recognition of pneumolysin by Toll-like receptor 4 confers resistance to pneumococcal infection. Proc. Natl. Acad. Sci. U. S. A. 100:1966-1971.

37. Hotchkiss, R.S., et al. 2001. Role of apoptosis in Pseudomonas aeruginosa pneumonia. Science. 294:1783.

38. Cheng, J., et al. 1994. Protection from Fas-mediated apoptosis by a soluble form of the Fas molecule. Science. 263:1759-1762.

39. Lehnardt, S., et al. 2002. The toll-like receptor TLR4 is necessary for lipopolysaccharide-induced oligodendrocyte injury in the CNS. J. Neurosci. 22:2478-2486

40. Laflamme, N., Echchannaoui, H., Landmann, R., and Rivest, S. 2003. Cooperation between toll-like receptor 2 and 4 in the brain of mice challenged with cell wall components derived from gram-negative and gram-positive bacteria. Eur. J. Immunol. 33:1127-1138.

41. Garcia-Bustos, J.F., Chait, B.T., and Tomasz, A. 1987. Structure of the peptide network of pneumococcal peptidoglycan. J. Biol. Chem. 262:15400-15405.

42. Aliprantis, A.O., et al. 1999. Cell activation and apoptosis by bacterial lipoproteins through tolllike receptor-2. Science. 285:736-739.

43. Hotchkiss, R.S., and Karl, I.E. 2004. Endothelial cell apoptosis in sepsis: a case of habeas corpus? Crit. Care Med. 32:901-902.

44. Takeuchi, O., et al. 1999. Differential roles of TLR 2 and TLR4 in recognition of gram-negative and gram-positive bacterial cell wall components. Immunity. 11:443-451.

45. Blasig, I.E., et al. 2001. NO and oxyradical metabolism in new cell lines of rat brain capillary 
endothelial cells forming the blood-brain barrier. Microvasc. Res. 62:114-127.

46. Berry, A.M., Yother, J., Briles, D.E., Hansman, D., and Paton, J.C. 1989. Reduced virulence of a defined pneumolysin-negative mutant of Streptococcus pneumoniae. Infect. Immun. 57:2037-2042.

47. Spellerberg, B., et al. 1996. Pyruvate oxidase, as a determinant of virulence in Streptococcus pneumoniae. Mol. Microbiol. 19:803-813.

48. Holtje, J.V., and Tomasz, A. 1975. Specific recognition of choline residues in the cell wall teichoic acid by the $\mathrm{N}$-acetylmuramyl-L-alanine amidase of Pneumococcus. J. Biol. Chem. 250:6072-6076.
49. Tomasz, A., Westphal, M., Briles, E.B., and Fletcher, P. 1975. On the physiological functions of teichoic acids. J. Supramol. Struct. 3:1-16.

50. Hoffmann, O., et al. 2002. Triptans reduce the inflammatory response in bacterial meningitis. J. Cereb. Blood Flow Metab. 22:988-996.

51. Pitrak, D.L., Tsai, H.C., Mullane, K.M., Sutton, S.H., and Stevens, P. 1996. Accelerated neutrophil apoptosis in the acquired immunodeficiency syndrome. J. Clin. Invest. 98:2714-2719.

52. Kim, C.N., et al. 1997. Overexpression of Bcl-X(L) inhibits Ara-C-induced mitochondrial loss of cytochrome $\mathrm{c}$ and other perturbations that acti- vate the molecular cascade of apoptosis. Cancer Res. 57:3115-3120.

53. Schwartz, D.C., and Cantor, C.R. 1984. Separation of yeast chromosome-sized DNAs by pulsed field gradient gel electrophoresis. Cell. 37:67-75.

54. Menzies, B.E., and Kourteva, I. 1998. Internalization of Staphylococcus aureus by endothelial cells induces apoptosis. Infect. Immun. 66:5994-5998.

55. Latz, E., et al. 2002. Lipopolysaccharide rapidly traffics to and from the Golgi apparatus with the toll-like receptor 4-MD-2-CD14 complex in a process that is distinct from the initiation of signal transduction. J. Biol. Chem. 277:47834-47843. 